\title{
Effects of pressure parameters on alumina made by powder injection moulding
}

\author{
Wen-Cheng J. Wei*, Rong-Yuan Wu, Sah-Jai Ho \\ Institute of Materials Science and Engineering, National Taiwan University, 1 Roosevelt Road, Section 4, Taipei, Taiwan 106, ROC
}

Received 31 December 1998; received in revised form 9 October 1999; accepted 25 October 1999

\begin{abstract}
The effects of injection molding pressure and holding time on the properties of injection moulded (IM) parts, and the pressurevolume-temperature (PVT) relationship of the plastic ingredient and alumina feedstocks were investigated. The properties of IM parts include the mass, dimension, surface flatness, green density, sintered density and four-point bending fracture strength of the test bars. The results reveal that the pressure-time traces where the gate pressure is increased from 22 to $117 \mathrm{MPa}$ and the holding time up to $75 \mathrm{~s}$, illustrate the trend of the property change under these pressures. High holding pressures ( $\geqslant 70 \mathrm{MPa})$ and longer holding time (more than $5 \mathrm{~s}$ ) would be favored to increase molded mass, dimension and to decrease the surface sinking of green pieces. The data also show that the pressures and holding time exert no significant influence on the bulk density of green parts, the sintered density nor the bending strength of sintered alumina. (C) 2000 Elsevier Science Ltd. All rights reserved.
\end{abstract}

Keywords: $\mathrm{Al}_{2} \mathrm{O}_{3}$; Density; Injection moulding; Sintering; Strength

\section{Introduction}

Ceramic injection moulding (CIM) is a technique combining the injection moulding of plastics and the processing of ceramic powders. ${ }^{1,2}$ The technique can offer the advantages of the fabrication of near-net-shape ceramic pieces with fairly complex configurations which would cut down the machining costs for the parts made by very hard materials. For these reasons, ceramic injection moulding has gained the attention of the ceramic industry in the past decade.

Injection pressure is one of the key processing parameters mentioned in several research works. ${ }^{1-4} \mathrm{~A}$ successful injection moulding process for a ceramic is, in fact, far more complex than simply dealing with the pressure and holding time. The mould temperature and the rheology of feedstocks are all important for the production of a defect-free IM part. In addition, new attachments, e.g. ultrasonic sensors ${ }^{3}$ or hot sprue ${ }^{5,6}$ for the mould, indeed provide a better control in the injection moulding process. The properties, including

* Corresponding author. Tel.: + 886-2-2363-2684; fax: +886-22363-4562.

E-mail address: wjwei@ccms.ntu.edu.tw (W.-C.J. Wei). shrinkage $^{7}$ and residual stresses ${ }^{8,9}$ of the CIM parts are analyzed and become very important for the manufacture of precision parts.

The cavity pressure of a complete IM cycle can be categorized in four distinct stages. ${ }^{1,3}$ The pressure is still non-existent at the initial stage, but increases somewhat due to the filling of a small amount of feedstock into the mould. The pressure keeps building up to the maximum value at the third stage and the cavity is quickly filled with molten feedstock. In the final stage, the screw can offer a holding pressure but is unable to move forward because the runner and the gate of the mould are nearly frozen.

Besides exerting a static pressure by the screw, the IM pressure can also be achieved by a backward-movement of the mould wall. ${ }^{10}$ This injection compression has proven to be very useful in reducing the residual stress in the IM part, which will greatly reduce distortion. Both pressuring arrangements have the same effects on the cavity pressure. The higher the holding pressure is, the greater the cavity pressure will be. In addition, several material properties change as the cavity pressure increases. One is the increase in the freezing temperature of feedstock, the other is the residual stress in that part. ${ }^{8}$ The residual pressure of the IM part is still detectable if the holding pressure is exerted until the mould opens. 
Other than the holding pressure, the cavity pressure is influenced by the temperature of the mould and increases as the temperature of the mould increases. The cavity pressure would gradually decay and vanish eventually if the temperature of the mould is low enough (e.g. $50^{\circ} \mathrm{C}$ ). ${ }^{5}$ The pressure drop (the difference between injection pressure and cavity pressure) is due to the solidification of feedstock and the friction at the mould surface. A poor mould design results in a great loss of moulding pressure.

The specific volume $\left(\mathrm{cm}^{3} / \mathrm{gm}\right)$ of feedstock reduces as the cavity pressure increases at a constant temperature. The melting temperature of a semicrystalline plastic ingredient will also increase. Thus, the feedstock solidifies earlier under a higher cavity pressure. The relationship of pressure-volume-temperature (PVT) of a feedstock is the best indicator of the behavior of materials during the IM process.

The reproducibility of shape and dimension is of great concern in the CIM industry. A firm understanding of feedstock shrinkage and its relationship to the IM pressure are necessary. In fact, the investigation of the effects of IM pressure and the holding time of pressure on the properties of IM piece is not seen in the literature.

The objectives of this research involve several aspects. The first is to measure the properties of alumina feedstock. It is important to know the PVT curve of the feedstock mixed with submicron $\mathrm{Al}_{2} \mathrm{O}_{3}$ powder. The second is to do a detailed measurement of the pressures inside a mould cavity and in the front of the gate, so that the reasons for pressure drop across a gate can be explained accordingly. Finally, other processing parameters are kept the same, only holding pressure $\left(P_{\mathrm{III}}\right)$ and holding time $\left(t_{\text {III }}\right)$ are varied. Thus, the properties of IM pieces, including the moulded mass, bulk density and dimensional change of the green pieces, the apparent density and fracture strength of the sintered samples are measured and interpreted as a function of two important parameters.

\section{Experimental procedure}

\subsection{Materials and materials processing}

\subsubsection{Materials}

The raw materials used in this study include alumina powder, polypropylene, paraffin wax, stearic acid, and $n$-heptane solvent. The alumina powder A-16SG was supplied by Alcoa Industrial Chemicals, USA. Polypropylene (PP, Formosa Plastic, Taiwan) and paraffin wax (PW, Nippon Serio, Japan) were used as either a binder or plasticizer, respectively, in the formulation to provide fluidity in the injection process. The PP is $95-$ $98 \%$ isotactic and $5-2 \%$ atactic reported by the vendor.
The crystalline fraction of PP in the feedstock will be discussed in Section 3.1. Stearic acid (SA, Nacalai Tesque, Japan) acts as a surfactant for the alumina and polymeric ingredients. The details of the properties of four materials are listed in Tables 1 and 2. The constitution of polymer additives is in a weight ratio of $\mathrm{PW}$ : PP: SA $=70: 25: 5$, and the mass ratio of alumina to plastic ingredients is $85: 15$, which is equivalent to a volume ratio of 56.6 to 43.4 , for the overall constitution.

\subsubsection{Kneading and granulation}

A twin $\Sigma$-type kneader (Ray-E Manufacture Co., Tainan, Taiwan) was used with a mixing bowl of $650 \mathrm{ml}$ and operated at a rate of $35 \mathrm{rpm}$. In the beginning of the kneading process, alumina was heated to $175^{\circ} \mathrm{C}$ in the kneader. Three chemical ingredients were then mixed with the powder in a sequence as indicated below: PP was first added to form a mixture. After mixing for 50 min, SA was then added and the temperature of the kneader was reduced to $50^{\circ} \mathrm{C}$. Ten minutes later, $\mathrm{PW}$ was gradually put in the bowl as the temperature of the mixture reached $>140^{\circ} \mathrm{C}$. Each constituent was mixed well with the alumina in the kneader in $10 \mathrm{~min}$. The dough-type mixture was then gradually granulated as the temperature of the bowl decreased to ca. $70^{\circ} \mathrm{C}$. One kneading and granulation process took approximately $90 \mathrm{~min}$.

\subsubsection{Injection moulding}

An injection moulding machine (CDC9000 SM50, CHEN HSONG, Co.) was operated according to the parameters indicated in Table 3. The feedstock was melted at $170^{\circ} \mathrm{C}$ and moulded into a mould (Fig. 1) of twin cavities which have the dimensions of

Table 1

Properties of $\mathrm{Al}_{2} \mathrm{O}_{3}$ powder

\begin{tabular}{ll}
\hline Properties & $\mathrm{Al}_{2} \mathrm{O}_{3}(\mathrm{~A}-16 \mathrm{SG})$ \\
\hline & \\
$\mathrm{BET}\left(\mathrm{m}^{2} / \mathrm{g}\right)$ & 9.0 \\
Particle size, $\mathrm{d}_{50}(\mu \mathrm{m})$ & 0.4 \\
Crystalline phase & $\alpha$ \\
Purity $(\%)$ & 99.7 \\
Impurity & $\mathrm{Na}_{2} \mathrm{O}(800 \mathrm{ppm}), \mathrm{SiO}_{2}(800 \mathrm{ppm})$, \\
& $\mathrm{Fe}_{2} \mathrm{O}_{3}(100 \mathrm{ppm}), \mathrm{MgO}(500 \mathrm{ppm})$ \\
\hline
\end{tabular}

Table 2

Polymeric materials used in this study

\begin{tabular}{llcc}
\hline Properties & \multicolumn{3}{l}{ Polymeric ingredients } \\
\cline { 2 - 4 } & Paraffin wax & Polypropylene & Stearic acid \\
\hline$T_{\mathrm{m}}\left({ }^{\circ} \mathrm{C}\right)$ & 68.0 & 170 & 71.9 \\
Specific gravity & 0.918 & 0.903 & 0.978 \\
\hline
\end{tabular}


$4.00 \times 5.15 \times 49.95 \mathrm{~mm}^{3}$. Additionally, the mould had a hot sprue constantly operating at $130^{\circ} \mathrm{C}$ throughout the entire experiment. The maximum pressure $\left(100 \% P_{\mathrm{III}}\right)$ indicated in the injection moulding machine was 137 $\mathrm{MPa}$ (an oil pressure). The variation of pressure from 5 to $95 \%$ used in the result reported later is the percentage of the maximum pressure.

\subsubsection{Debinding and sintering}

An organic solvent $n$-heptane (total isomers is more than $9.8 \%$, water content $\leqslant 0.01 \%$, free acid $\leqslant 0.01 \%$ )

Table 3

Injection molding parameters of alumina feedstock at various stages

\begin{tabular}{lcccc}
\hline Parameter stage & 1 & 2 & 3 & 4 \\
\hline Injection velocity $(\mathrm{ml} / \mathrm{s})$ & 19.2 & 19.2 & 32 & 3.2 \\
Pressure $(\%)$ & 30 & 30 & $\mathrm{X}^{\mathrm{a}}$ & 80 \\
\hline Barrel temperature profile $\left({ }^{\circ} \mathrm{C}\right)$ & 150 & 160 & 170 & 170 \\
Temperature $\left({ }^{\circ} \mathrm{C}\right)$ of mold & & \multicolumn{2}{c}{50} \\
Holding time (s) at stage III & & \multicolumn{4}{c}{ Y } & \\
\hline
\end{tabular}

a $X$ (injection pressure): $5,25,50,75$, or $95 \%$ of $137 \mathrm{MPa}$, the maximum injection molding pressure.

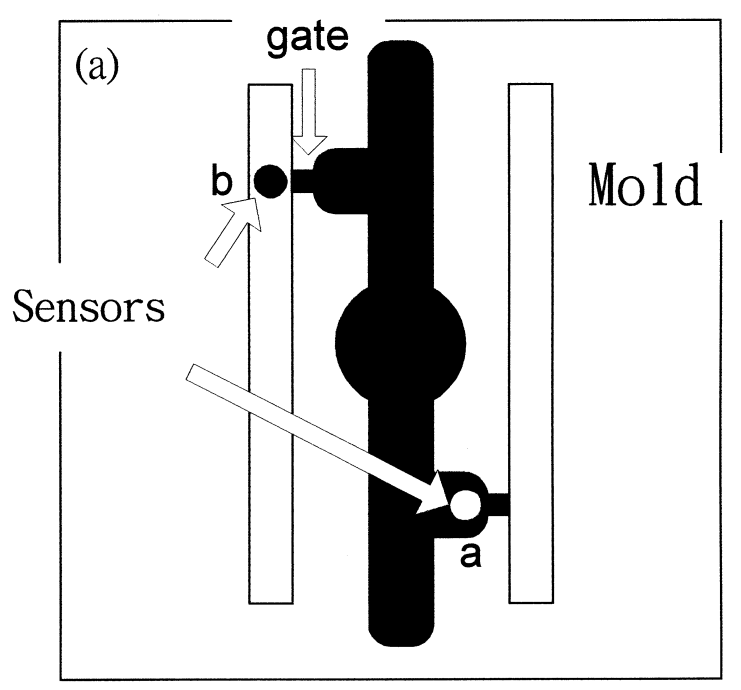

(b)

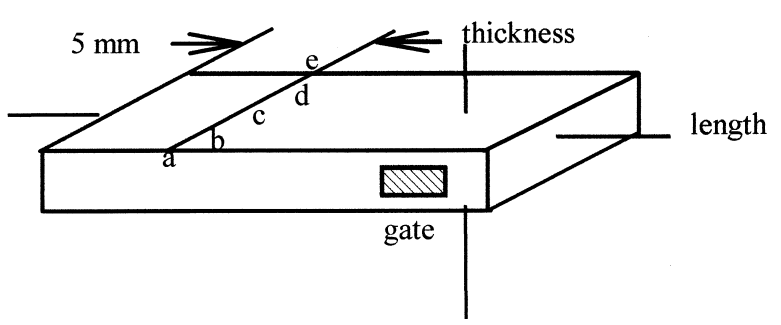

Fig. 1. (a) Schematic diagram of the injection mold illustrating the positions of pressure sensors. Position a: in front of the gate, position $b$ : behind the gate. (b) Schematic diagram of the dimensions of the test bar. was used to extract PW and SA in the IM specimens. The solvent debinding was conducted at $60^{\circ} \mathrm{C}$ and held for $2.5 \mathrm{~h}$. After drying, the samples were subject to thermal debinding according to the conditions indicated in Table 4. The samples after the de-binding process were checked before sintering to ensure that the surfaces were free from any visual defects. The samples were then heated at a rate of $10^{\circ} \mathrm{C}$ to the sintering temperature of $1580^{\circ} \mathrm{C}$ holding for $1 \mathrm{~h}$.

\subsection{Characterization}

\subsubsection{Pressure measurement}

The pressure sensor (Kistler 6159A, Kistler Instrument Corp., USA) attached with an amplifier (Kistler 5039A-312) was installed in the mould, as shown in Fig. 1 , for direct measurement of the cavity pressure. The electronic signal was converted to a pressure value and recorded by a 486 personal computer in a real time scale.

\subsubsection{Material properties}

The green density of the IM pieces was obtained by a water replacement method (Archimedes' method). The sintered ceramic pieces before bulk density measurement were boiled in water and then measured according to ASTM372-73. The sintered samples for the testing of fracture strength were surface ground using 325 mesh diamond wheel following the procedure previously specified. ${ }^{12}$ The four-point bending test was conduct on a dynamic testing instrument (MTS810, MTS, USA) with upper and lower spans of 10 and $30 \mathrm{~mm}$ used to evaluate the bending strength of the alumina test bar. ${ }^{13}$

The PVT behavior of the feedstocks was determined by the PVT-100 system (SWO, Germany). The test condition utilized different isobaric processes, from high temperature to room temperature at a cooling rate of $5^{\circ} \mathrm{C} /$ min to modify the condition of injection moulding. Before testing, the feedstock was pre-pressurized at 19.6 MPa to degas in the cell.

\subsubsection{Dimension measurement}

In order to reveal the surface sinking of the IM piece, the surface profile crossing the width of the IM samples was measured using a coordinate measuring machine (CMM, Poli Co., Italy). Three dimensions, thickness,

Table 4

Heating schedule of the thermal debinding for $\mathrm{Al}_{2} \mathrm{O}_{3}$ parts

\begin{tabular}{lccrrl}
\hline Stage & 1 & 2 & 3 & 4 & 5 \\
\hline Ramping rate $\left({ }^{\circ} \mathrm{C} / \mathrm{min}\right)$ & 2 & 2 & 5 & 10 & $\begin{array}{l}\text { Furnace } \\
\text { cooling }\end{array}$ \\
Isothermal temperature $\left({ }^{\circ} \mathrm{C}\right)$ & 200 & 260 & 400 & 1000 & - \\
Holding time $(\mathrm{h})$ & 0.3 & 2.0 & 0 & 0.5 & - \\
\hline
\end{tabular}


length and width, of each sample were also checked with a micrometer (Sylvac Co., Swiss) to a precision of $\pm 0.01 \mathrm{~mm}$.

\section{Results and discussion}

\subsection{Properties of feedstocks}

It is important to prevent surface slumping of IM parts during solidification. A IM part with a large crosssection would have higher chance remaining thermal stresses. The surface of the part sustains compressive pressure and inward forces as the interior solidifies. Therefore, a high holding pressure is often used before the gate freezes to balance the volume shrinkage. Without the holding pressure, severe defects, e.g. shrinkage voids and cracks, are produced. If the IM pressure, volume shrinkage, and cooling are under controlled, the IM ceramic piece can be free of defect.

The specific volume of the mixture of the $\mathrm{Al}_{2} \mathrm{O}_{3}$ feedstock changing with the testing pressure is reported in Fig. 2(a). The feedstock consists of $\mathrm{Al}_{2} \mathrm{O}_{3}$ and polymeric mixture in a mass ratio of $85: 15$. If the volume shrinkage of the $\mathrm{Al}_{2} \mathrm{O}_{3}$ is treated as a incompressible matter, the volume change of the binder in feedstock can be calculated by taking the volumetric effect of $\mathrm{Al}_{2} \mathrm{O}_{3}$ powder out from the expansion. The result of the PVT

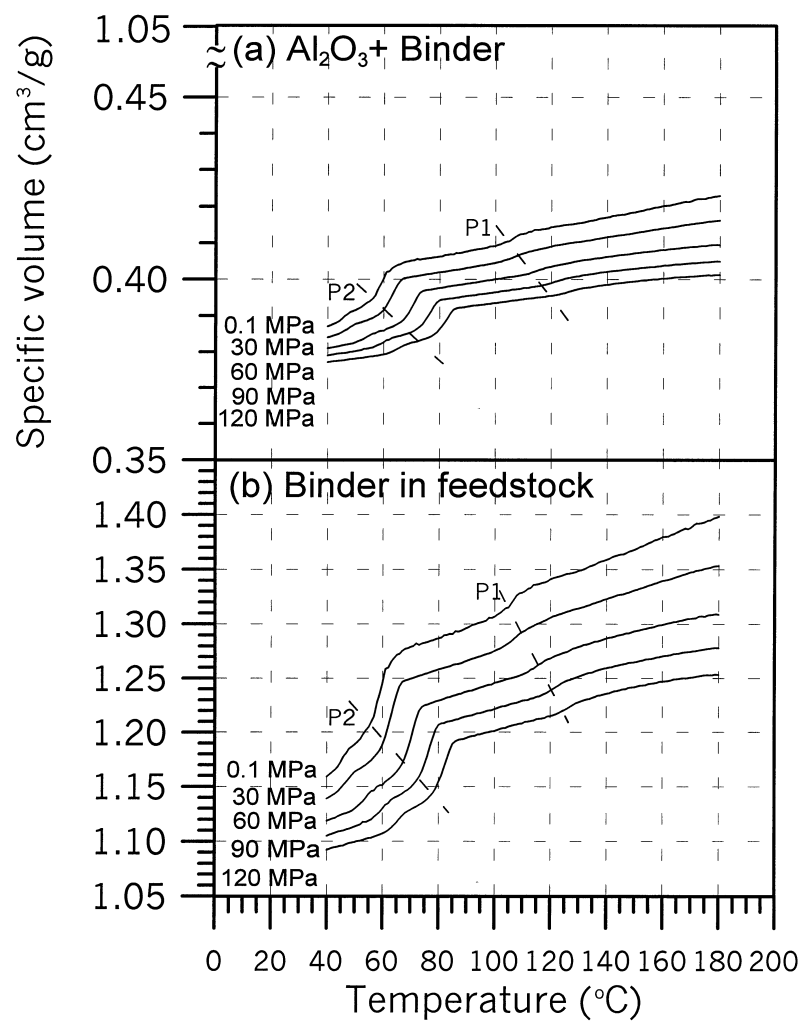

Fig. 2. Pressure-volume-temperature (PVT) curves of (a) $\mathrm{Al}_{2} \mathrm{O}_{3}$ feedstock (b) binder in the feedstocks expressed in an isobaric condition. of the polymeric mixture in $\mathrm{Al}_{2} \mathrm{O}_{3}$ feedstock is shown in Fig. 2(b). Fig. 2(a) and (b) have the features in common.

The PVT curves in Fig. 2 all perform 2 transitions, as the broken lines indicated. The transition temperatures increase as the testing pressure, e.g. P1 increases from 102 to $120^{\circ} \mathrm{C}$ as the pressure increases from 0.1 to 120 $\mathrm{MPa}$. The formation of the transition is due to the change of the physical states of the binder.

Fig. 3 is the DSC diagram of the mixture of polymeric ingredients and the alumina feedstock that have undergone heating and cooling at $10^{\circ} \mathrm{C} / \mathrm{min}$ from 30 to $180^{\circ} \mathrm{C}$. Both had gone through similar preparation procedures. The heating curves show that the PW melts at 41.5 and $56.6^{\circ} \mathrm{C}$. The PP melts at $138-139^{\circ} \mathrm{C}$. As the melts cool, only two exothermic peaks at $100 \pm 2$ and $53 \pm 2^{\circ} \mathrm{C}$ are identified. The DSC results in cooling stage are consistent to two transitions $\left(53\right.$ and $\left.100^{\circ} \mathrm{C}\right)$ in the PVT curves tested at $0.1 \mathrm{MPa}$.

The solidification of poorly crystalline PP and the crystallization of $\mathrm{PW}$ are thought to correspond to the exothermic peaks. The melting enthalpy of a pure PP was determined to be $30.9 \mathrm{~J} / \mathrm{g}$ and the enthalpy of the $P P$ in the feedstock is $26.0 \mathrm{~J} / \mathrm{g}$. The exothermic heat of the feedstock integrated from the cooling profile is apparently less than the endothermic heat (Fig. 3). The difference implies that the crystalline fraction of the thermally cycled polymeric mixture is less than that of as-prepared feedstock. It is also noted that the exothermic and endothermic heats of the alumina feedstock is smaller than that of the polymeric mixture.

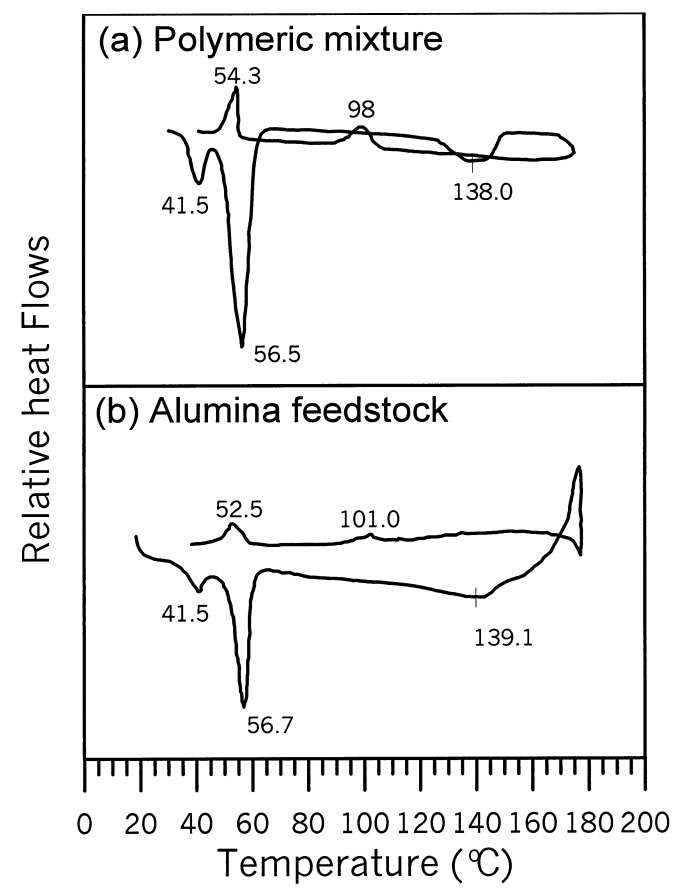

Fig. 3. DSC diagrams of (a) polymeric mixture and (b) alumina feedstock tested by heating and cooling at $10^{\circ} \mathrm{C} / \mathrm{min}$ between 30 and $180^{\circ} \mathrm{C}$. 
The volume dilation of the feedstock is $4 \%$ when changing the pressure from 120 to $0.1 \mathrm{MPa}$ isothermally at $170^{\circ} \mathrm{C}$, as shown in Fig. 2(a). The thermal shrinkage is $7.3 \%$ when reducing the temperature from 170 to $50^{\circ} \mathrm{C}$ isobarically at $0.1 \mathrm{MPa}$. The difference of $3.3 \%$ indication the net contraction of the melted binder as it cools from $170^{\circ} \mathrm{C}$ and solidifies. It is noted that the specific volume change of the feedstock and binder is 3.3 and $4.7 \%$, respectively, from 0.1 to $90 \mathrm{MPa}$ at $40^{\circ} \mathrm{C}$. The volume change of the feedstock is reduced by $1.4 \%$ because the ceramic powder shrinks far less than that of polymeric mixture. The alumina powder of high elastic modulus reduces the compressibility of the feedstocks.

The slope of the curve of the PVT diagram in Figs. 2 is the coefficient of volumetrically thermal expansion (CTE) of materials. The CTE value changes at the transition point of the phases. A large shrinkage often results in cracking and surface slumping of poorly designed IM parts. The prevention of those defects can be achieved by adjusting the holding pressure and the temperature of the mould.

\subsection{Variation of gate and cavity pressure}

Fig. 4 shows the pressure traces in the mould cavity obtained at different holding pressures $\left(P_{\mathrm{III}}\right)$ from 6.8 to $130 \mathrm{MPa}$ at a mould temperature of $55^{\circ} \mathrm{C}$. The curves can be categorized into two groups. One is the sample prepared by the oil pressure of $6.8 \mathrm{MPa}$; the others are prepared equally or over the injection pressure 34.3 $\mathrm{MPa}$. In the former, the pressure curve increases to the maximum in a fraction of second, then decreases to zero due to the cold shrinkage of the IM piece, as shown in curve (a) in Fig. 4. The pressure is not recovered afterward. However, different pressurizing behavior takes place in front of the gate [Fig. 5 curve (a)] where the

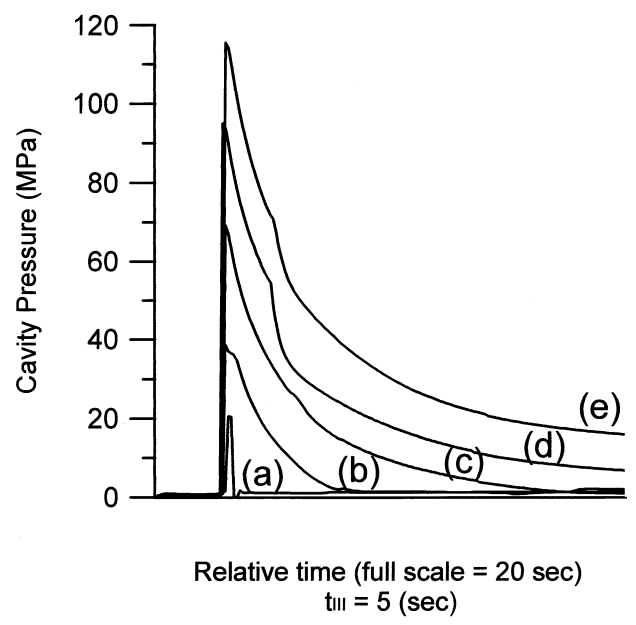

Fig. 4. Pressure traces in the cavity for different holding pressures, either (a) $5 \%$, (b) $25 \%$, (c) $50 \%$, (d) $75 \%$ or (e) $95 \%$ at a mold temperature of $55^{\circ} \mathrm{C}$. pressure is kept at a level of about $20 \mathrm{MPa}$. The reasons for maintaining the pressure at the gate are mainly due to the effect of the screw of the IM machine via the runner. It is certain that the feedstock at the gate and in the cavity is solidified less dependent on the injection pressure.

Figs. 4 and 5 also reveal the maximum pressure trace measured in the cavity and in front of the gate for a constant holding time of $5 \mathrm{~s}$ and a mould temperature of $55^{\circ} \mathrm{C}$. The pressure in the stage of maximal pressurizing is sustained at nearly the same level as at the gate. However, the lapping time at maximal pressure decreases from 3.6 to $1.1 \mathrm{~s}$ as the pressure increases from 25 to $90 \%$, as shown in Fig. 5. The higher the oil pressure is, the shorter the lapping time will be. It is believed that the decrease of the solidification temperature of the melt feedstock under hydrostatic pressure has shortened the lapping time as shown in Fig. 2.

The cavity pressure (Fig. 4), which rapidly decreases as it passes the maximum pressure, has performed differently. The authors believe that the shrinkage of a cooling IM piece is responsible for the variation. The change of the pressure and temperature of an IM piece in the mould has a track correspondent to Fig. 2(a) which may start from the point of high to low pressures. The temperature and pressure traces in Fig. 2(a) are in fact different for the surface and center of the IM piece. The time needed for solidification of the feedstock at the gate is the major issue for the termination of pressure transferred from the runner to the cavity. Zhang et al. ${ }^{11}$ have calculated the stress distribution and theoretical solidification time for the thick IM part. They concluded that the time would become shorter as the holding pressure increases, and the residual stress increases as the injection pressure increases. The curves in Fig. 2(a) appear to show that the temperature, if it is higher

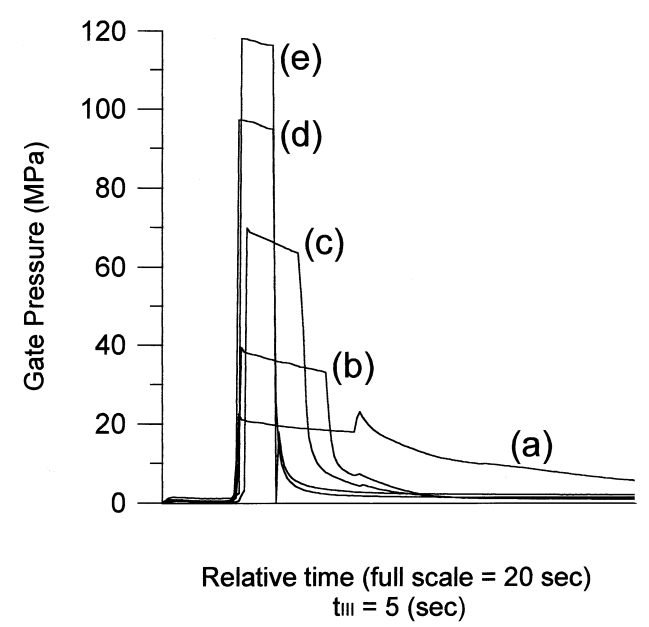

Fig. 5. Pressure trace measured in front of the gate for a constant holding time of $5 \mathrm{~s}$ and a mold temperature of $55^{\circ} \mathrm{C}$, but different $\%$ of oil pressures, either (a) $5 \%$, (b) $25 \%$, (c) $50 \%$, (d) $75 \%$ or (e) $95 \%$. 
than $90^{\circ} \mathrm{C}$, of the feedstock under a pressure of $70 \mathrm{MPa}$ still allows the materials to be flowable. But the feedstock which contacts with the cold surface $\left(55^{\circ} \mathrm{C}\right)$ of the mould is solidified. The residual stresses at the center of the moulded part start to build up and to be tensile as the IM part cools to room temperature.

The maximum pressures at the gate and cavity are depicted in Fig. 6 as a function of $P_{\mathrm{III}}$. Two maximum pressures exhibit no significant deviation to each other. However, they show a deviation away from the origin in Fig. 6, which means that the injection pressure exerted by the IM machine does not maintain a linear relationship between the cylinder pressure and the percentage of output. Therefore, the results reported in the latter sections show the holding pressure in the scale of maximum pressure $(\mathrm{MPa})$.

Fig. 7 reveals the influence of the holding period $\left(t_{\mathrm{III}}\right)$ of injection on the pressure traces at the gate for different holding pressures $\left(P_{\text {III }}\right)$ from 6.8 to $102.7 \mathrm{MPa}$. Normally, a full injection of the mould [Fig. 1(a)] can be completed in $5 \mathrm{~s}$ if the holding pressure is greater than $25 \mathrm{MPa}$. It is clear that the runner is not solidified yet in $5 \mathrm{~s}$. But once the injection pressure increases to a level greater than $34 \mathrm{MPa}$, an apparent pressure drop is observed as the finish of third stage injection, e.g. (c) and (d) pressure traces in Fig. 7. However, the scale of the pressure drop is more evident when a shorter holding period $\left(t_{\mathrm{III}}\right)$ is used. The pressure drop in the transition from the $P_{\mathrm{III}}$ to $P_{\mathrm{IV}}$ stage may be accompanied with a reverse flow of the melted feedstock in the runner. It is seen that the pressure will be totally cancelled if only $1 \mathrm{~s}$ of the injection $t_{\mathrm{III}}$ is completed. This clearly indicates the fluidizing condition of the melt in the runner. A flowable melt in the runner is allowing the residual pressure to totally dissipate.

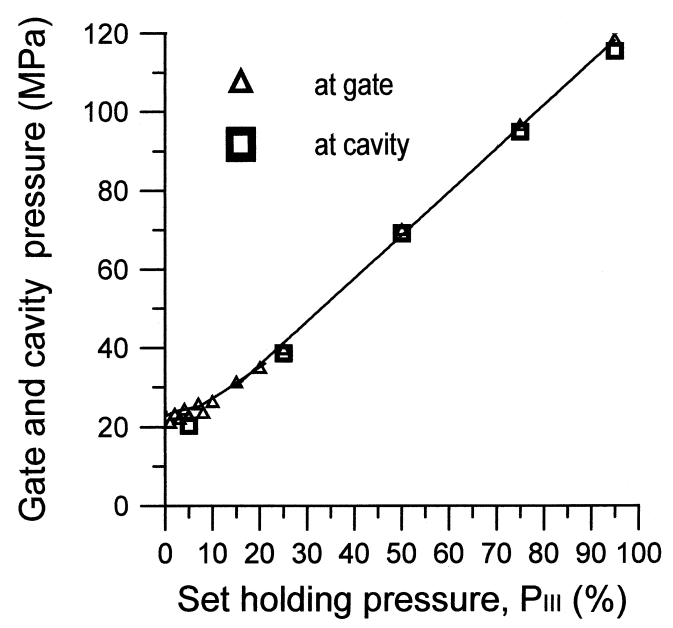

Fig. 6. Maximum pressures at gate or cavity plotted against the holding pressure $\left(P_{\mathrm{III}}, \%\right)$ at constant mold temperature $55^{\circ} \mathrm{C}$ for the injection molding of the alumina feedstocks.

\subsection{Physical properties of IM parts}

Fig. 8 reveals the mass change of the specimen with respect to its holding period $\left(t_{\mathrm{III}}\right)$ in the cavity. A sharp increase of the mass is observed in the first $5 \mathrm{~s}$ of holding, and the curve of the mass becomes saturated to a constant value after a moment of pressure holding. This is consistent with the early suggestion that the mass of viscous feedstock needed to fill the same volumetric cavity under a higher holding pressure is more than those under a lower pressure (e.g. 130-6.8 MPa case). Therefore, a $5 \mathrm{~s}$ period is needed to fill in the cavity and to build its injection pressure.

The net mass of the IM samples after release from the mould is mainly proportional to the injection pressure, as shown in Fig. 9. There is a $4.8 \%$ mass increase when the injection pressure is elevated from 22 to $117 \mathrm{MPa}$.
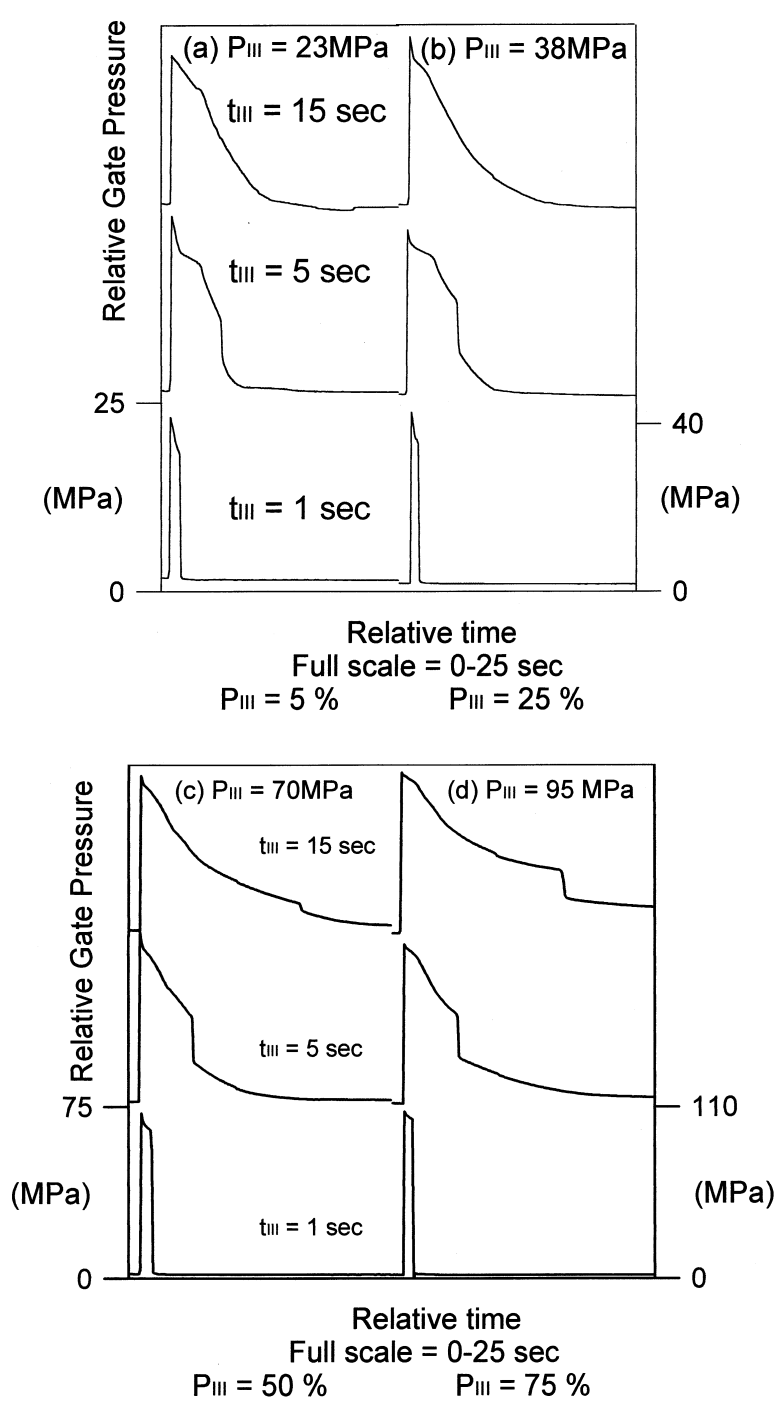

Fig. 7. Pressure traces measured in front of the gate (gate pressure) for different $\%$ of the oil pressures $\left(P_{\mathrm{III}}\right)$ and times with a mold temperature $55^{\circ} \mathrm{C}$. Holding pressure (a) $5 \%$; (b) $25 \%$; (c) $50 \%$; (d) $75 \%$. 
The increase of mass from the factor of the pressure elevation maybe a result of the increase of the density of the IM piece. These soft materials, mainly including PP and PW, will have a smaller specific volume at a higher pressure under constant temperature, as shown in Fig. 2. The plastic ingredients have a higher compressibility than the ceramic powder. Higher pressure caused a more viscous feedstock to enter the same mould and produce a heavy specimen.

The green density of the IM parts is shown in Fig. 10 in which the density of the low-pressure-made is only a

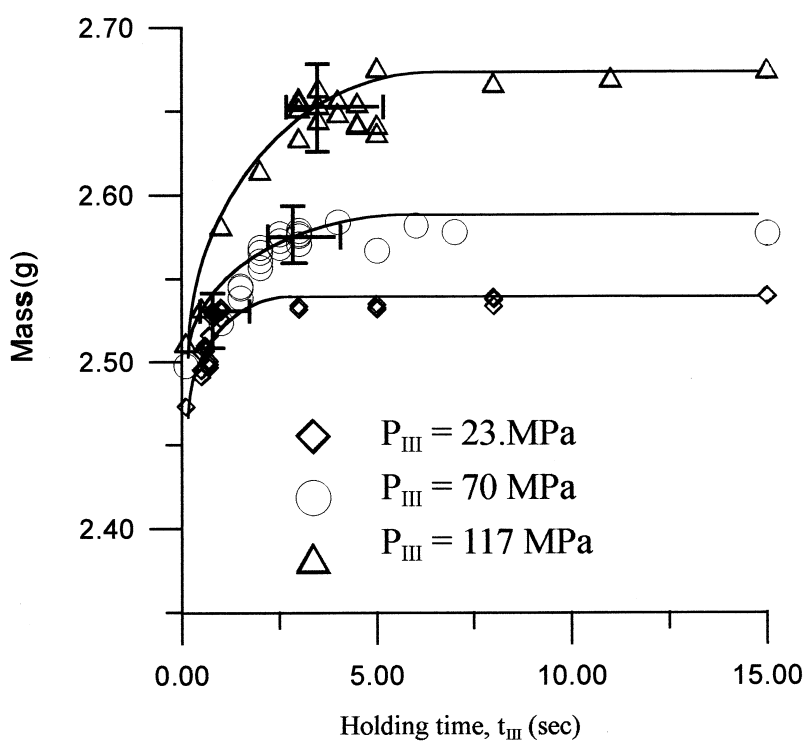

Fig. 8. Mass of injection molding parts plotted against holding time under same injection velocity but at three different $P_{\text {III }}$ pressure.

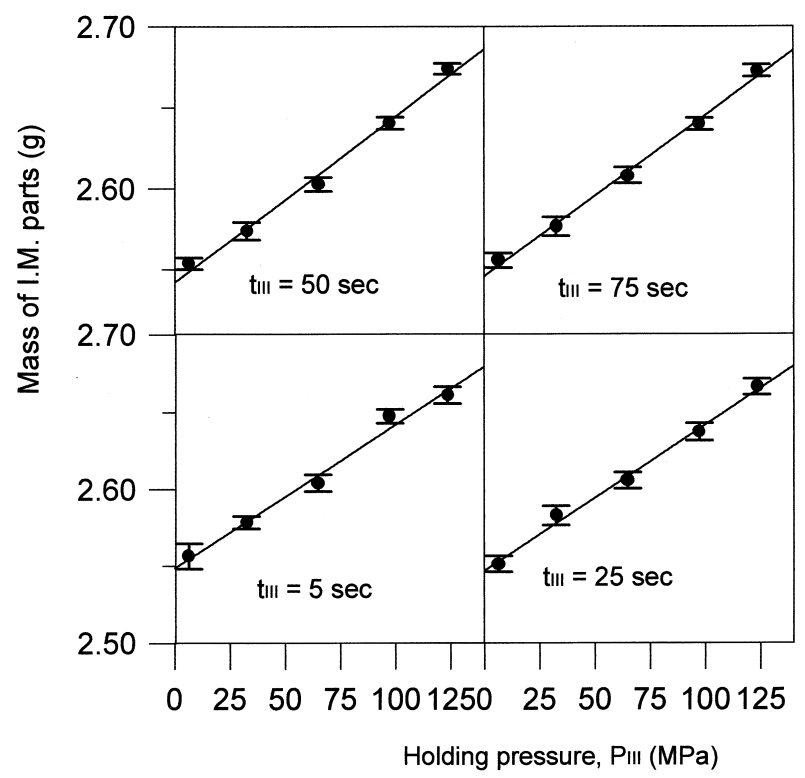

Fig. 9. Mass of injection molded parts plotted against the pressure $\left(P_{\mathrm{III}}\right)$ varied from 5 to $95 \%$ and different holding times $\left(t_{\mathrm{III}}\right)$. fraction of a percentage less than that made by a holding pressure higher than $70 \mathrm{MPa}$. The bulk density of the specimen was not greatly influenced by the injection pressure. The $4.8 \%$ difference in the mass of those green pieces is compensated by various volume shrinkages, and so causes the green density to be a little different after the IM process. Only the variation of the bulk density is larger $( \pm 0.4 \%)$ for those prepared by a lower injection pressure $(<70 \mathrm{MPa})$. The injection pressure and holding time affect the filling mass of the viscous feedstock into the cavity. But the influence on the green density and dimension of IM parts is very complex.

Two dimensions of the IM samples were measured and reported in Fig. 11. One is the length along the axis direction; the other is the thickness, as shown in Fig. 1(b). The dimensional shrinkage along the length is only $0.4 \%$ as the pressure changed from 22 to $117 \mathrm{MPa}$. However, the thickness shows a greater difference of $1.7 \%$ within the pressure difference. It is normally proposed that the polymeric molecules will preferentially align to the flowing direction. ${ }^{14}$ Therefore, the cooling shrinkage of the IM piece along the axis should be less than that along the direction of thickness. In addition, the results in Fig. 11 give the sensitivity of the dimensional shrinkage with respect to the pressure which exerts less influence on the flowing direction of a piece.

Warpage of the IM specimens is reported in Fig. 12 as a function of the holding pressure and the position along the width $[5 \mathrm{~mm}$ away from the end of the test bar, as shown in Fig. 1(b)]. Note that the centre of the test pieces has the lowest position (set at a value of $0.0 \mathrm{~mm}$ ) along the width direction, as the "c" position indicated in Fig. 12. Qualitatively, a specimen prepared by a greater oil pressure ( $>70 \mathrm{MPa}$ ) will result in less shrinkage. The variation of the profile is something consistent with the temperature distribution during

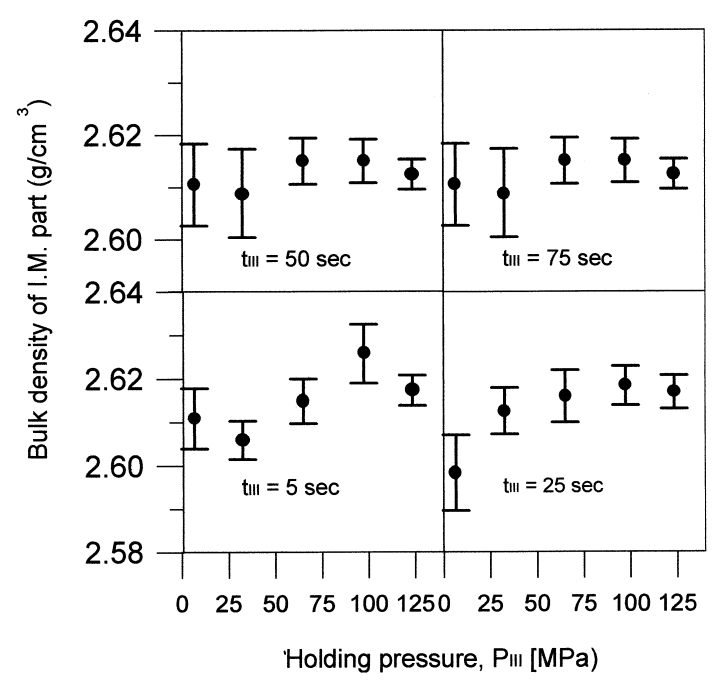

Fig. 10. Green density of injection molding parts as a function of the $P_{\text {III }}$ pressure and holding period. 


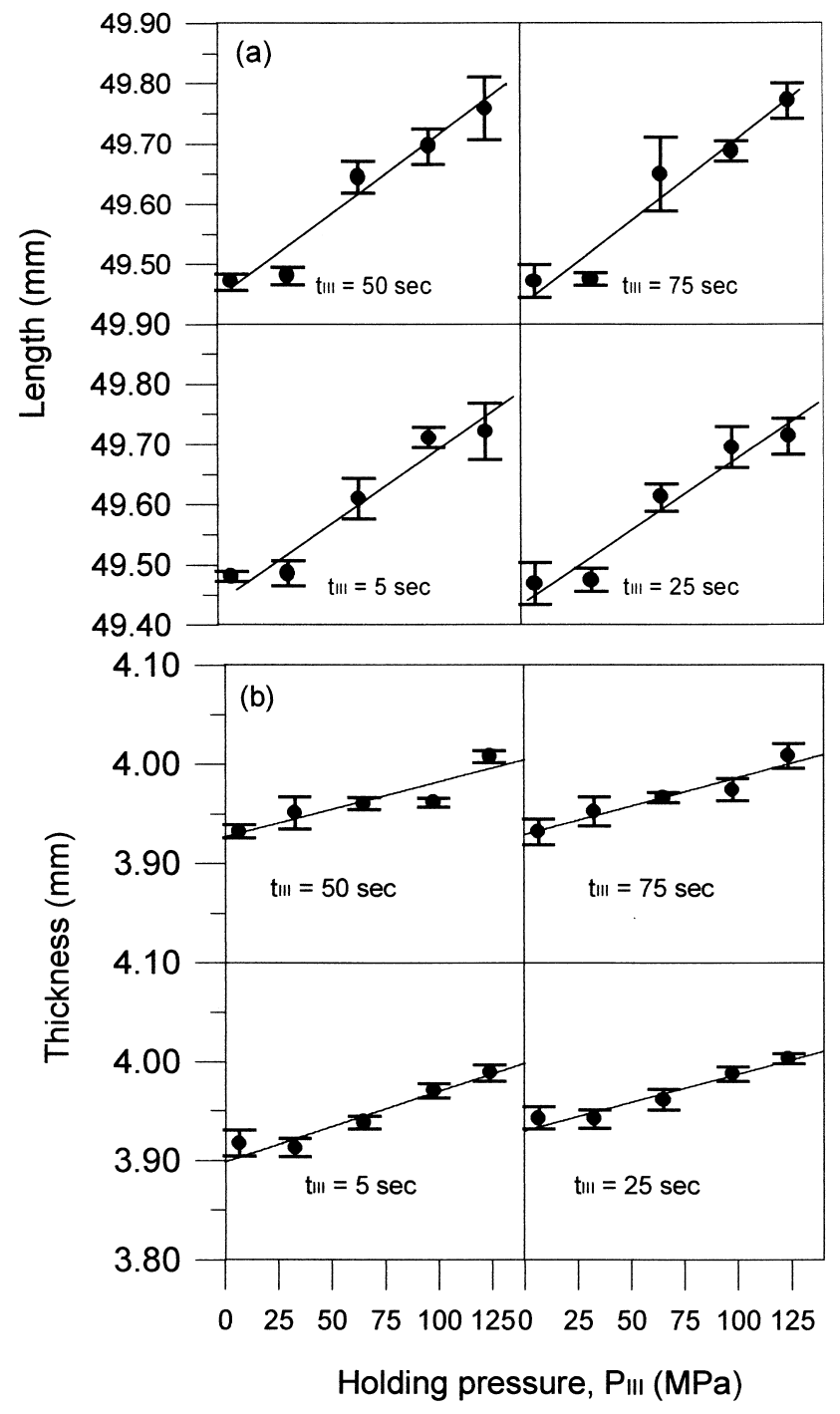

Fig. 11. The changes of (a) the length and (b) the thickness $(\mathrm{CH})$ of injection molding parts as a function of the pressure and holding period.

cooling and the residual stresses in the IM part. ${ }^{6,11} \mathrm{~A}$ higher compressive stress acts on the outer surface as a result of a higher IM pressure. However, the outer surface undergoes less volume shrinkage when it is cooled, as shown in Fig. 2(a). It is found that $70 \mathrm{MPa}$ is a pressure critical in producing a specimen with a flatter surface due to less shrinkage during cooling.

\subsection{Properties of sintered parts}

The alumina samples after solvent and thermal debindings were subject to sintering. The density results are shown in Fig. 13. Neither the holding time nor holding pressure in the injection stage shows a systematic influence on the sintering density of the specimens. Nearly all of the measured densities lie between the $97-98 \%$ theoretical density (T.D.), and a standard deviation $\pm 0.5 \%$

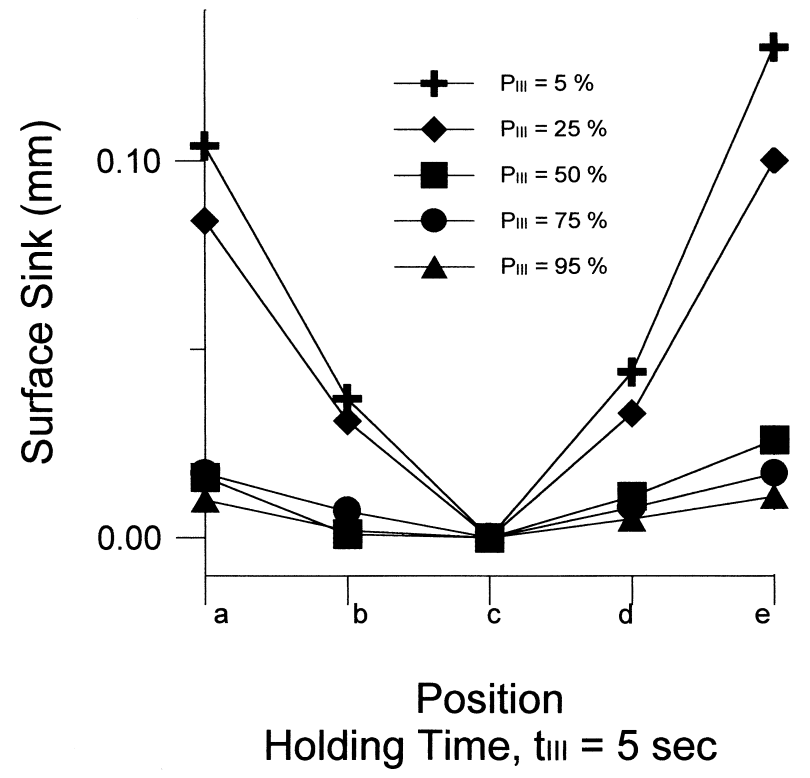

Fig. 12. Surface sink of specimens as a function of position and the $P_{\text {III }}$ pressure. Note that the lowest position $(0.0 \mathrm{~mm})$ is at the center of specimen width. The positions of a to e are shown in Fig. 1(b).

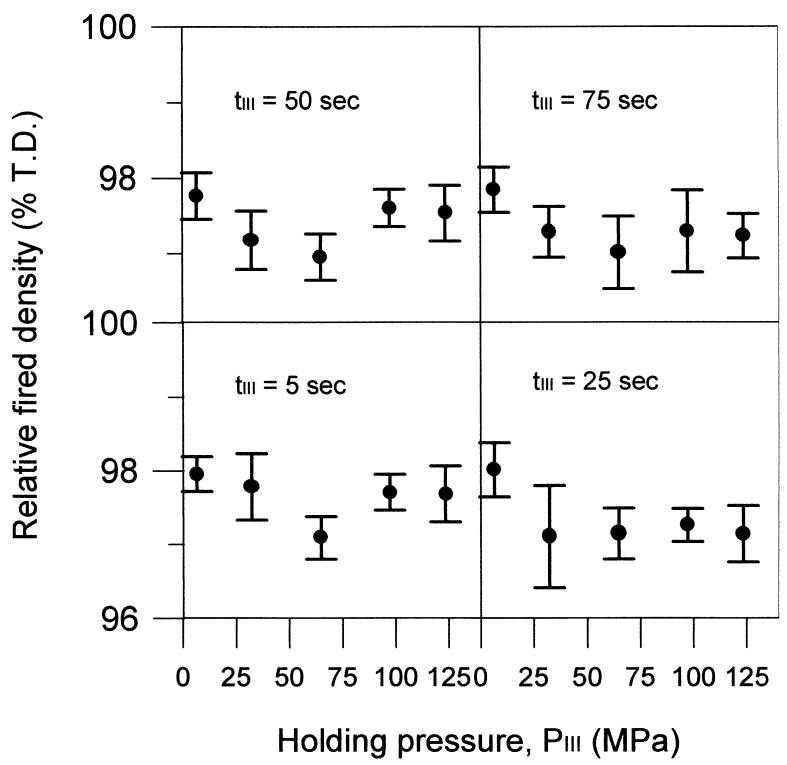

Fig. 13. Relative fired density of injection molding parts varied with the $P_{\mathrm{III}}$ pressure and holding period.

T.D. of the density is achieved in our experiments. There seems to be no significant difference between the density of these sintered parts. The deviation of the density in the Fig. 13 can possibly be the result of an experimental error, and not closely correlate to injection pressure $P_{\mathrm{III}}$ and period $t_{\mathrm{III}}$.

The bending strength of the sintered parts was investigated. The strength is in the range of $390 \mathrm{MPa}$. Since the distributions of these strength values nearly overlap, no apparent difference is found between the 


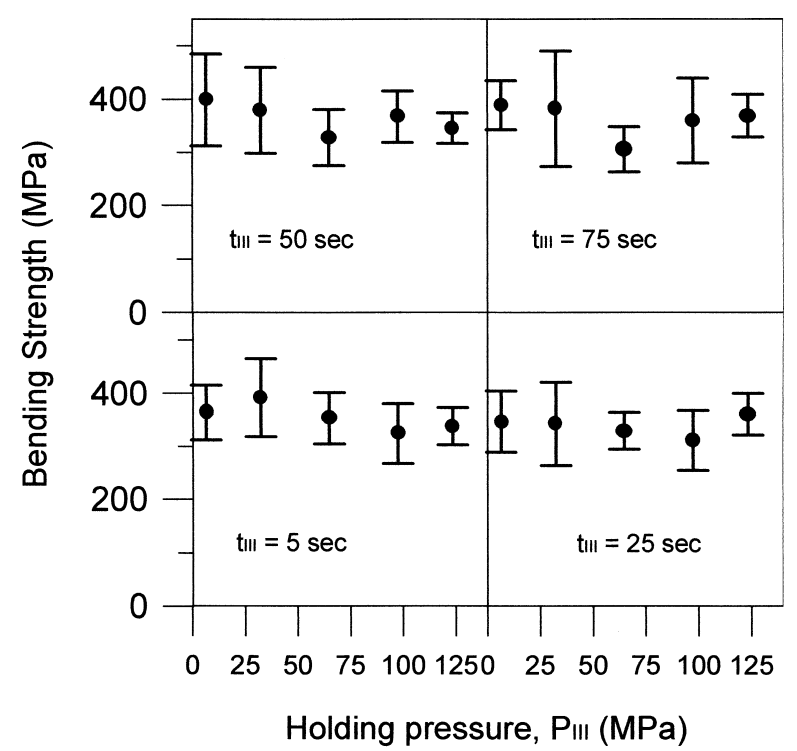

Fig. 14. Bending strength of alumina samples plotted against the $P_{\mathrm{III}}$ pressure and holding period.

performance of these sintered parts made by various pressures and holding time. From the viewpoint of processing optimization, the processing parameters related to the pressurizing step of IM exert less influence on the final density and bending strength of the products. It is believed that a low-pressure injection moulding process has the potential to fabricate the ceramic parts similar in sintered properties as those made by a higher injection pressure, but the precision of part dimension should be emphasized.

\section{Conclusion}

The injection moulding of alumina feedstocks with a solid loading of $85 \%$ in mass and a ratio of plastic additives PW:PP:SA $=70: 25: 5$ was used to prepare the feedstocks for the investigation of the effects of pressuring parameters during injection moulding. The results show:

1. PVT diagrams of the polymeric materials and alumina feedstock show that the compressibility of the polymeric ingredients and the transition points change during pressurizing step and are important factors in interpreting the variation of the pressures in the cavity and at the gate.

2. At low pressure of $20 \mathrm{MPa}$, the pressure is not transferred through the gate. The cavity pressure drops in a second due to the cooling shrinkage of the moulded piece from the surface of a mould. At a high pressure, the solidification point of the melted feedstock is lowered, resulting in a rapid freezing of the gate and a shorter lapping time of the maximum pressuring stage.
3. The injection pressure $\left(P_{\mathrm{III}}\right)$ has a strong influence on the properties of the green pieces. The holding time $\left(t_{\mathrm{III}}\right)$ of the pressurizing step only affects the properties if it is run shorter than $5 \mathrm{~s}$. The mass of the IM pieces has as much as a $4.8 \%$ increment if the pressure changes from 22 to $117 \mathrm{MPa}$. However, the green density of the pieces is nearly identical except that the standard deviation of the lowpressure-injected pieces is greater.

4. The variation of the dimensional shrinkage along the flowing direction is smaller (ca. $0.4 \%$ ) than the shrinkage along the thickness direction (1.7\%). The pressure exerts less influence on the flow direction of a piece. A $P_{\mathrm{III}}$ of $70 \mathrm{MPa}$ is needed for this alumina feedstock to obtain a reasonably flat surface. Below the pressure, the surface has an apparent surface sinking.

5. The sintered samples have a sintered density of 97 $98 \%$ T.D. in a standard deviation of $\pm 0.5 \%$ T.D., and a bending strength of $390 \mathrm{MPa}$. Of these samples made under various pressures and holding periods, the standard deviations of these sintered properties, including sintered density and bending strength are hardly differentiated. The results imply that an injection moulding process using a lower pressure has the potential to fabricate the ceramic parts similar in sintered properties as those made under a higher injection pressure.

\section{Acknowledgements}

The authors thank the helpful discussion with Professor Sheng-Yu Yang and Kuen-Shyang Hwang and also acknowledge the funding given by the National Science Council in Taiwan under the contact no. NSC86-2216-E002-020 and NSC87-2216-E-002-034.

\section{References}

1. German, R. M., Powder Injection Molding. MPIF, Princeton, New Jersey, 1990.

2. Mutsuddy, B. C. and Ford, R. G., Ceramic Injection Molding. Chapman and Hill, London, 1995.

3. Hens, K. F., Tooling and instrumentation for quality, 1995 Intern. Powd. Inj. Mold. Sym, 19-21 July, Penn State Scanticon, State College, USA, 1995.

4. Zhang, J. G., Edirisinghe, M. J. and Evans, J. R. G., The use of modulated pressure in ceramic injection molding. J. Eur. Ceram. Soc., 1989, 5, 63-72.

5. Zhang, J. G., Edirisinghe, M. J. and Evans, R. G., The control of sprue solidification time in ceramic injection moulding. J. Mat. Sci., 1989, 24, 840-848.

6. Zhang, T. and Evans, J. R. G., The use of a heated sprue in the injection moulding of large ceramic sections. Br. Ceram. Trans. J., 1993, 92(4), 146-151.

7. Thomas, M. S. and Evans, J. R. G. Non-uniform shrinkage in ceramic injection molding. Br. Ceram. Trans. J. 1988, 87(1); 22-26.

8. Kostic, B., Zhang, T. and Evans, R. G., Effect of molding 
condition on residual stresses in powder injection molding. Int. J. Powd. Metall., 1993, 29(3), 251-257.

9. Fox, R. T. and Lee Daeyoug, Analysis of temperature effects during cooling in powder injection molding. Int. J. Powder Metall., 1994, 30(2), 221-229.

10. Yan, S. Y. and Lien, L., Experimental study of injection compression molding of cylindrical parts. Adv. Polym. Proc., 1996, 15(3), 205-223.

11. Zhang, T. and Evans, J. R. G., The solidification of large sections in ceramic injection molding: Part I. Conventional molding. $J$. Mat. Res., 1993, 8(1), 187-194.

12. Chyr, B. C., Wei, W. C. J. and Koo, C. H., Flexural strength and surface grinding properties of alumina. Chin. J. Mat. Sci., 1993, 25(3), 173-180.

13. JIS R1601, Testing methods for flexural strength (modulus of rupture) of high performance ceramics.

14. Struik, L. C. E., Orientation effects and cooling stress in amorphous polymers. Polymer Eng. Sic., Mid-August, 1978, 18(10), 799. 